\title{
The ICES Working Group on Oceanic Hydrography: A Bridge From In-situ Sampling to the Remote Autonomous Observation Era
}

OPEN ACCESS

Edited by:

Sanae Chiba,

Japan Agency for Marine-Earth

Science and Technology, Japan

Reviewed by:

Christoph Waldmann,

University of Bremen, Germany

Oscar Schofield,

Rutgers University, United States

*Correspondence:

César González-Pola cesar.pola@ieo.es

Specialty section: This article was submitted to

Ocean Observation,

a section of the journal Frontiers in Marine Science

Received: 31 October 2018 Accepted: 20 February 2019 Published: 19 March 2019

Citation:

González-Pola C, Fratantoni P. Larsen KMH, Holliday NP, Dye $S$, Mork KA, Beszczynska-Möller $A$ Valdimarsson $H$, Trofimov A, Parner $H$,

Klein $H$, Cisewski B, Fontán A,

Lyons K, Kolodziejczyk N, Graña R,

Linders J, Wodzinowski T, Goszczko I and Cusack C (2019) The ICES

Working Group on Oceanic Hydrography: A Bridge From In-situ Sampling to the Remote Autonomous

Observation Era.

Front. Mar. Sci. 6:103. doi: 10.3389/fmars.2019.00103

\begin{abstract}
César González-Pola ${ }^{1 *}$, Paula Fratantoni ${ }^{2}$, Karin M. H. Larsen ${ }^{3}$, N. Penny Holliday ${ }^{4}$, Stephen Dye ${ }^{5}$, Kjell Arne Mork ${ }^{6}$, Agnieszka Beszczynska-Möller ${ }^{7}$, Hedinn Valdimarsson ${ }^{8}$, Alexander Trofimov ${ }^{9}$, Hjalte Parner ${ }^{10}$, Holger Klein ${ }^{11}$, Boris Cisewski ${ }^{12}$, Almudena Fontán ${ }^{13}$, Kieran Lyons ${ }^{14}$, Nicolas Kolodziejczyk ${ }^{15}$, Rocío Graña ${ }^{1}$, Johanna Linders ${ }^{16}$, Tycjan Wodzinowski ${ }^{17}$, Ilona Goszczko ${ }^{7}$ and Caroline Cusack ${ }^{14}$

${ }^{1}$ Spanish Institute of Oceanography (IEO), Oceanographic Center of Gijón, Gijón, Spain, ${ }^{2}$ NOAA NMFS Northeast Fisheries Science Center, Woods Hole, MA, United States, ${ }^{3}$ Faroe Marine Research Institute, Torshavn, Faroe Islands, ${ }^{4}$ National Oceanography Centre, Southampton, United Kingdom, ${ }^{5}$ Centre for Environment, Fisheries and Aquaculture Science, Lowestoft, United Kingdom, ${ }^{6}$ Institute of Marine Research, Bergen, Norway, ${ }^{7}$ Institute of Oceanology Polish Academy of Sciences, Sopot, Poland, ${ }^{8}$ Marine and Freshwater Research Institute, Reykjavik, Iceland, ${ }^{9}$ Knipovich Polar Research Institute of Marine Fisheries and Oceanography, Murmansk, Russia, ${ }^{10}$ International Council for the Exploration of the Sea, Copenhagen, Denmark, ${ }^{11}$ Federal Maritime and Hydrographic Agency (BSH), Hamburg, Germany, ${ }^{12}$ Thünen Institute of Sea Fisheries, Bremerhaven, Germany, ${ }^{13}$ AZTI Marine Research, Pasaia, Spain, ${ }^{14}$ Marine Institute, Galway, Ireland, ${ }^{15}$ LOPS laboratory (UBO-CNRS-Ifremer-IRD), University of Brest, Plouzané, France, ${ }^{16}$ Swedish Meteorological and Hydrological Institute, Norrköping, Sweden, ${ }^{17}$ National Marine Fisheries Research Institute, Gdynia, Poland
\end{abstract}

The ICES (International Council for the Exploration of the Sea) Working Group on Oceanic Hydrography (WGOH) was established in the late 1970's with the aim of gathering experts in physical oceanography to provide regular science-based assessments of the North Atlantic hydrographical condition (basically termohaline fields). From the beginning, the WGOH has relied on repeated long-term in-situ sampling at key sites around the North Atlantic, the Nordic Seas and adjacent shelf seas. An annual Report on Ocean Climate (IROC), produced by the WGOH since the late 1990's, summarizes trends in regional hydrography and identifies patterns linking these changes across the North Atlantic. Regional analyses are prepared by local experts who are directly involved in the monitoring programs responsible for collecting data presented in the report. An interactive webpage created in 2013 allows users to browse and download data that inform the IROC. Within the last two decades the physical oceanography community has evolved quickly incorporating technological advances such as autonomous devices into classical in-situ sampling programs. The WGOH has embraced such technological developments without diverting focus from ongoing in-situ long-term monitoring programs. Having longstanding experience synthesizing data and expertise from a large number of operational programs spanning an extensive international footprint, the WGOH has a unique perspective to offer the global ocean observing community. Here we discuss how we might foster connections with ICES to benefit the GOOS (Global Ocean Observing System) community.

Keywords: ocean climate, hydrography, timeseries, in-situ sampling, periodical report, science to policy, North Atlantic 


\section{INTRODUCTION}

Since its founding in 1902, the International Council for the exploration of the Sea (ICES) has aimed to increase the scientific knowledge of the marine environment and its living resources and to use this knowledge to provide unbiased, nonpolitical advice to competent authorities ${ }^{1}$. Primarily focused in the North Atlantic, ICES consists of a network of marine scientists that seek to coordinate on ocean monitoring and research, with the aim of providing the best available science to decision-makers.

ICES internal coordination relies on a complex structure that builds on the work carried out by up to 150 Expert Groups (EGs). EGs gather scientists from different countries to address specific topics within the broad spectrum of marine science. EG members work throughout the year, typically meeting in person once per year to work through a series of assigned tasks. No financial support is provided by ICES for EGs, so members need to find funds from their home institutions or projects. This presents a challenge to members and can compromise engagement, especially in periods of scarce resources. However, the long-term continuity of most EGs indicates that the funds invested in their activities are beneficial.

ICES established the Working Group on Ocean Hydrography (WGOH) within this framework in 1976 (ICES, 1977) to further the work done by the Hydrography Committee on data management and to coordinate cooperative hydrographic research within the framework of the World Meteorological Organization (WMO). At that time, 15 years ahead of the creation of the Global Ocean Observing System (GOOS), ICES represented a major partnership within the ocean community and a valuable opportunity for international networking, thereby inspiring several physical oceanographers to join the group. A review of the WGOH activity up to 2009 is given by Holliday et al. (2010) within the framework of the Oceans09 Conference. Currently, the WGOH is composed of nearly 50 members from 35 institutions and 18 countries around the North Atlantic region.

The WGOH has been active, meeting on a yearly basis, for more than 40 years. During these four decades the way we observe ocean hydrography has changed profoundly, evolving from primarily traditional vessel-based in-situ sampling to progressive incorporation of remote autonomous observation technologies. Also, the ocean observing community has grown, initiatives promoting international coordination have emerged, and comprehensive near-realtime ocean state analyses have been established as a public service. Meanwhile, the WGOH has continued to evolve while preserving the essence of its work aimed at providing ICES with information on ocean hydrography as a basis for marine ecosystems research and resources evaluation. Next we present our view on the future of the WGOH, highlighting its long-standing foundation which is rooted in international cooperation.

\section{OCEAN CLIMATE STATUS. THE IROC}

A central component of WGOH annual meetings since its formation has been a session devoted to regional reviews of ocean climate. These reviews are based on data from existing monitoring programs run by individual countries or as international collaborations, sometimes in the framework of fisheries management programs. Considered together, the detailed regional reviews inform our understanding of North Atlantic variability and may be used to develop joint strategies for global monitoring.

Over time it became clear that this joint review of ocean status was valuable to other expert groups working on topics related to marine environment and ecosystems under the ICES umbrella. In 1999, the WGOH published the first review of previous year ocean climate conditions as an Annex of the WG official Report (Turrel, 1999), naming it Annual ICES Ocean Climate Status Summary (IAOCSS). A year later, the IAOCSS became a standalone document. In 2004 major formatting changes were introduced that helped homogenize the presentation (Hughes and Lavín, 2004), and key illustrations were included summarizing changes observed across the North Atlantic. In 2006 the IAOCSS was renamed ICES Report on Ocean Climate (IROC) (Hughes and Holliday, 2006). That report first incorporated the ISAS large-scale gridded fields produced by the LOPS laboratory and Coriolis operational oceanography center, a product which exploits the expansion of Argo autonomous profilers array (Gaillard et al., 2016).

In 2013 the WGOH implemented an interactive web version of the IROC $^{2}$ in collaboration with the ICES Data Center (Figure 1). Now the regional timeseries are updated as soon as observations are available during the year and the data can be freely downloaded. An archive of IROC reports is available on the website and summary highlights for current year conditions are posted immediately following the WG annual meeting. A recent improvement is the inclusion of newly developed indices, such as the Subpolar Gyre Index (Berx and Payne, 2017; Hátún and Chafik, 2018), which serves as a proxy for the strength and extent of the large scale circulation in the North Atlantic. Current efforts are focused on further standardization with regards to data processing (i.e., anomaly computation) and report layout (presentation of regional circulation maps, timeseries display, etc.).

WGOH analyses are based predominantly on existing repeated long-term in-situ hydrographic observations at stations and sections around the North Atlantic, the Nordic Seas and adjacent shelf seas, including the coastal, shelf and deep ocean. The idea behind the IROC is that regional experts perform analyses applying their specialized knowledge of a region to identify the most relevant available observational timeseries that support their assessment of hydrographic change. In this sense it is important to highlight that the IROC web is not a data repository but a heterogeneous collection of specialized timeseries. Most series are derived from CTDs deployed at fixed stations or along sections, with data extracted from either a single

${ }^{2}$ https://ocean.ices.dk/iroc/ 


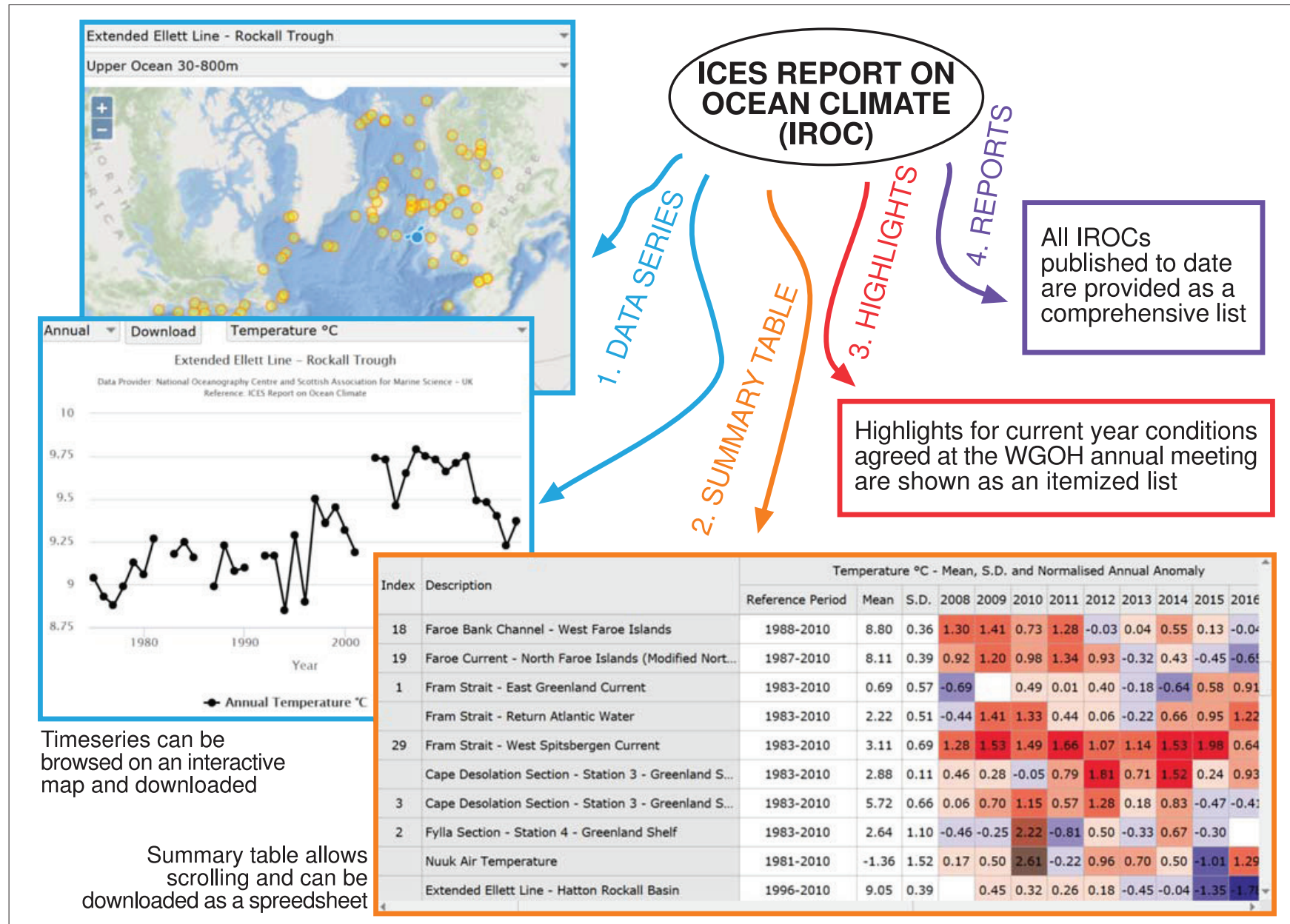

FIGURE 1 | Composite of content provided by the web version of the IROC report as of 2018. The portal is organized into four tabs containing data and elaborated information.

level or as vertical averages across a relevant water layer. Other series include long-term records of surface hydrography, sea-ice extent, atmospheric variables or other derived products such as heat content or estimated flows. Some of the timeseries reported in the IROC are the longest in the world and become more valuable to climate science with each passing year of continued measurement. These timeseries are not just long but also carefully analyzed by regional experts, thus of high quality to study and detect climate variability. Figure 2 shows some statistics of the current timeseries used for the IROC as of its latest published issue (González-Pola et al., 2018).

\section{THE WGOH AND THE GLOBAL OCEAN OBSERVING SYSTEM}

The WGOH has served as a network to physical oceanographers in the North Atlantic for decades. While most science emerging from the observational systems that feed the IROC are performed independently by WGOH members within their science groups, collaborative studies have also emerged (e.g., Holliday et al., 2008;
Holt et al., 2012; Hughes et al., 2012; Mork et al., 2014). Besides science, most outreach is achieved through the production of the IROC, currently used as a quick guide to environmental conditions for assessments and in support of other scientific studies (e.g., Nøttestad et al., 2015; Punzón et al., 2016; Widmer et al., 2016; Townhill et al., 2017; Brander, 2018). To continue the success of the IROC, the WGOH is continually seeking new ways to engage with a burgeoning global ocean observing community and to distinguish the IROC in an increasingly crowded field of ocean status reports. Generally speaking, internal concerns deal with the role of the WGOH in the future world of global ocean observations.

\subsection{Ocean Status Reports, End-User Needs and the Science-to-Policy Pathway}

The need for continuous monitoring, systematic analysis and quick release of data and derived products is the foundation of what is known as operational oceanography. The aim of the oceanographic community has long been to follow the lead of the more advanced meteorological services, expecting that monitoring programs are coordinated and oceanographic data 
A

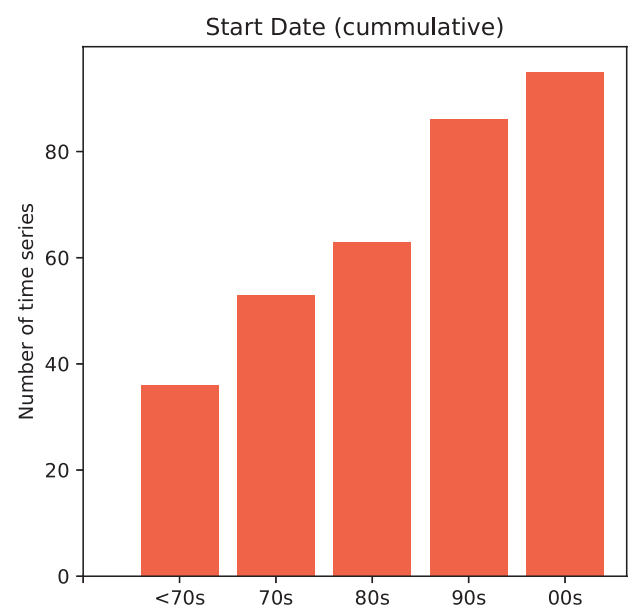

C

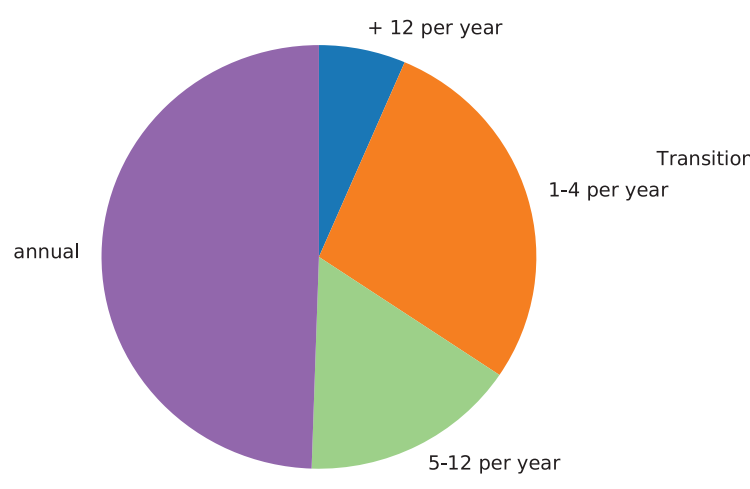

B

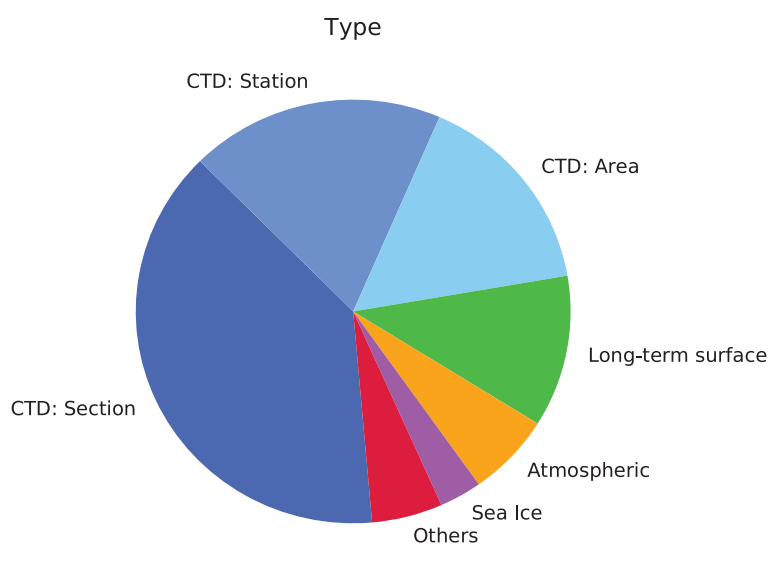

D

Region

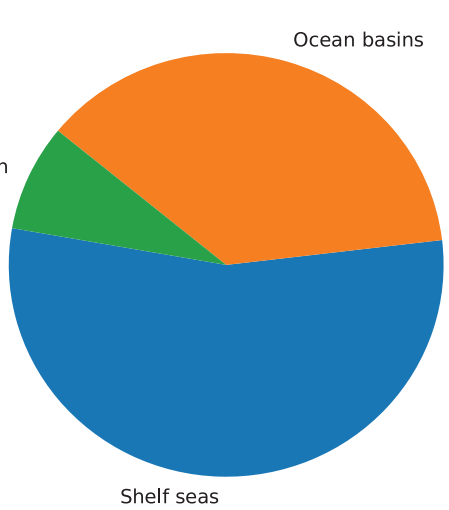

FIGURE 2 | Basic properties of timeseries included in the IROC. The report currently includes 95 timeseries from 76 locations, provided by 32 organizations across 15 countries. (A) Histogram of the starting dates of the timeseries grouped by decade (cummulative), (B) timeseries type: where "others" accounts for modeled flow, heat content anomaly, fresh water anomaly and spatial extent of specific water masses (i.e., the Cold Intermediate Level), (C) timeseries sampling frequency, (D) oceanic region, where 'Transition' includes stations over continental slopes and within straits.

are gathered systematically using standardized procedures and are freely distributed as soon as possible. The GOOS program has managed to gather the efforts of several institutions/consortia in this direction.

Along with increasing data availability, gridded products and reanalysis have been used as a means of objectively synthesizing information, which can then be described in science-based reports that aim to provide easy-to-understand summaries to end users. The Intergovernmental Panel on Climate Change (IPCC) has been publishing global assessment reports every 5-8 years since 1990 (IPCC, 1990). Similarly, the National Oceanic and Atmospheric Administration (NOAA) has been publishing an annual State of the Climate report as a standalone peer-reviewed publication since 1996 (Halpert and Bell, 1997). Since 1994, the World Meteorological Organization (WMO) has published their annual Statement on the Global Climate (WMO, 1994). Over time, these three international flagship reports have introduced specific sections dedicated to the recent evolution of ocean climate, focusing on the ocean heat content, salinity, ocean circulation and more recently considering biogeochemistry. Current issues (IPCC, 2013; Hartfield et al., 2018; WMO, 2018) provide a high degree of detail in their ocean chapters. Region-specific ocean climate state reports are also being produced individually by countries either regularly or without predefined sequence.

In parallel to international efforts and those of individual countries, the European Union has developed Copernicus ${ }^{3}$ as a joint Earth Observation and Monitoring program built upon the in-situ observational capabilities of member states and satellite developments by the European Space Agency. Copernicus provides environmental services to the scientific community, policy-makers and general users. The Copernicus Marine Service has since 2016 released the Ocean State Report (von Schuckmann et al., 2018), dealing both with the Global Ocean and regional European Seas. Independent of Copernicus, the European Union

${ }^{3}$ www.copernicus.eu 
has set the Marine Strategy Framework Directive ${ }^{4}$ (MSFD) as a legal framework to protect the marine environment from anthropogenic pressures across European waters. Contrary to large initiatives within GOOS in which sampling relies on voluntary efforts by institutions and countries, the MSFD enforces the establishment of (i) monitoring programs, (ii) objective environmental targets and (iii) a program of measures designed to achieve or maintain an objectively defined "Good Environmental Status". Ocean Climate conditions are considered by the MSFD as an indirect anthropogenic pressure on the ocean environment, hence the monitoring of large-scale hydrographic conditions is a background prerequisite required for the MSFD as a whole. Interpretations on whether the MSFD enforces the development of specific large-scale monitoring programs for the background basic ocean variables have been varied (González et al., 2016).

As indicated, this profusion of ocean climate reporting raises concern about the current degree of complementarity and/or redundancy. Accordingly, the $\mathrm{WGOH}$ is concerned that the IROC remains relevant, distinguished in purpose and value to its users. The essential question, common to any reportproducing team, is whether it is useful to end-users and if so how it should evolve to become more useful. Success requires a solid understanding of user needs. Sitting within the ICES, a body organized to encourage interdisciplinary networking, the WGOH-IROC is in a unique position to provide information and advice that is timely and relevant to the management of living marine resources. Oceanographic conditions are fundamental to understanding and predicting species distribution, forecasting recruitment, improving ecological models, etc. but marine ecology/fisheries scientists find it difficult to distinguish between available environmental products and effectively apply them to their work (ICES, 2018). The WGOH delivers expertise through the IROC and member engagement, which is becoming increasingly important as focus continues to shift toward ecosystem-based approaches for the management of marine resources (Dickey-Collas, 2014).

Several WGOH members are closely engaged with fisheries and environmental management activities, participating in multidisciplinary assessments and studies. In our experience, collaborators typically seek a succinct summary of the regional oceanography that can be used to frame a particular study, or a representative index of ocean variability that can be correlated with other measures of ecological change. In this sense, a simple representative timeseries or a few summarizing highlights are often sufficient. Hence, we expect the standard IROC user to focus on a specific region, while keeping in mind the general broader ocean context. A major strength of the IROC lies in the detailed regional analyses contributed by local experts from data products specifically tailored to the regional oceanography. Future developments of the IROC should not overlook this strength. Direct contact with potential users indicates that further developments may include a regional interpretation

\footnotetext{
${ }^{4} \mathrm{http}$ //ec.europa.eu/environment/marine/eu-coast-and-marine-policy/marinestrategy-framework-directive
}

of available operational products and assessment of ocean state forecasts.

Along with improvements to the IROC, it is critical to develop a strategy for promoting its use, aimed at demonstrating the relevance of the report in future observing programs and its value for end-users. The current approach uses the ICES outreach strategy coordinated by a communications and publications department. IROC report highlights are published on the ICES news web page ${ }^{5}$ before publication of the full report, and extensive social network activity is triggered along the process. A major target in the $\mathrm{WGOH}$ is having the report ready in summer to facilitate its use at the ICES Annual Science Conference. In parallel to ICES efforts, WGOH members use their own science networks and conference attendances to promote the IROC. Future success of the IROC will be tracked through its bibliometric performance, with the recent introduction of digital identifiers (doi) in Cooperative Research Reports.

ICES' goal of providing unbiased science-based advice to competent authorities requires full involvement of all EGs in the science-to policy pathway. The transfer of scientific advances into practical management tools builds upon the underlying idea that permanent two-way communication and strong coordination are pivotal. Current ICES structure relies on two main pillars, the Science and the Advisory Committees, who jointly struggle to facilitate such coordination ${ }^{6}$. WGOH-IROC forms a critical bridge between data collected by independent scientists/institutions/countries for research and environmental monitoring, and actual policy advice.

\subsection{IROC Timeseries and GOOS}

As seen in section 2, the $\mathrm{WGOH}$ analyses reported in the IROC are mostly based on the existence of long-term highquality repeat hydrographic timeseries, primarily derived from in-situ sampling. These timeseries are considered representative at regional scale, providing notable coverage of the shelf seas and ocean boundaries. Traditional in-situ sampling was the only option for most of the twentieth century but the last two decades have yielded outstanding advances in routine automated sampling of the ocean in terms of oceanographic fixed buoys (WMO-IOC, 2018), the Argo array (Riser et al., 2016) and more recently regular glider missions (Rudnick, 2016).

The introduction of new technology will allow for the continuation of several long-established timeseries in the North Atlantic. A relevant case is the Ellett Line (Holliday and Cunningham, 2013), that started in 1975 and has been covered by an annual cruise until now. Beginning in 2018 this regular cruise will be superseded by a new observation system (OSNAP $\left.{ }^{7}\right)$ utilizing moored arrays, glider missions and biannual shipboard sampling. The representative regional IROC timeseries will be continued using these data supplemented by observations from the Argo array. In another example, high-frequency subsurface

\footnotetext{
${ }^{5}$ www.ices.dk/news-and-events/news-archive/news/Pages/Ocean-climatehighlights.aspx

${ }^{6}$ www.ices.dk/community/groups/Pages/wkscience2advice.aspx-Workshop on translating science into advice. 2018.

${ }^{7}$ The Overturning in the Subpolar North Atlantic Program www.o-snap.org
} 
sampling by the Norwegian Ocean Weather Station "M" was discontinued with the removal of the last weather ship in 2010 (Yelland et al., 2009). As a replacement, hydrographic observations from this location derive now from subsurface instrumentation in the framework of OceanSITES ${ }^{8}$ plus research ships visits up to five-six times per year. Finally, surface temperature measurements collected via ship of opportunity at $52^{\circ} \mathrm{N}$ along the southern North Sea were discontinued in 2002 with the removal of the ferry line. However, the timeseries may now continue using observations from a nearby Smartbuoy (See Figure 77, p.81, in González-Pola et al., 2018).

Currently, only a portion of the IROC timeseries are systematically being incorporated into Global Operational Databases and hence contributing effectively to GOOS. This issue is a major concern of the $\mathrm{WGOH}$, already highlighted in the previous white paper authored by the group (Holliday et al., 2010). One challenge is that most hydrography derived from national monitoring programs are only available in delayed mode, while current demands expect real-time availability. In addition, many repeat hydrography programs do not meet the GO-SHIP ${ }^{9}$ sampling criteria and hence datasets are not incorporated through JCOMMOPS ${ }^{10}$. The lack of a home for classical hydrographic cruises has been highlighted as a weakness of the current JCOMMOPS structure. On the other hand, the ICES Data Center has long focused on hosting delayed mode CTD and discrete water bottle data from ICES areas, which are routinely incorporated into the US World Ocean Database and Atlas ${ }^{11}$ and made available to the global community.

As automated sampling develops, science programs are beginning to consider the relative benefits of more traditional in-situ sampling. Oceanographic cruises are becoming more multidisciplinary, with biogeochemistry often included as a mandatory component, while hydrography stands as a basic record. Further, in-situ hydrography remains essential for the groundtruthing of data from autonomous vehicles and profiling floats. Hence, while autonomous systems may supplement in-situ measurements made via ship or moored array in long-standing programs, we argue that these traditional observations will be required well into the future. Despite the delayed delivery, IROC timeseries offer significant added value to GOOS programs. In particular, (i) IROC observations sample the deep ocean in a variety of locations across the North Atlantic, filling a major gap in present day GOOS where deep observations (> $2000 \mathrm{~m}$ ) are limited to GO-SHIP sections (Deep Argo floats and deep gliders still have a long way to fully cover the gap) and (ii) IROC observations bridge a gap between the blue ocean and regional seas, shelves and oceanic boundaries, where most classical monitoring programs take place but the Argo network cannot access.

\footnotetext{
${ }^{8}$ www.oceansites.org

${ }^{9}$ The Global Ocean Ship-Based Hydrographic Investigations Program www.go-ship.org/DatReq.html

${ }^{10}$ WMO-IOC Joint Technical Commission for Oceanography and Marine Meteorology in-situ Observing Programmes Support Centre www.jcommops.org

${ }^{11}$ www.nodc.noaa.gov/about/oceanclimate.html
}

\section{CONCLUSION AND OUTLOOK}

For decades, the ICES-WGOH has provided ICES and the oceanographic community with information on the condition of the North Atlantic Ocean by updating and reviewing results from standard long-standing hydrographic sections and stations. WGOH continues a long tradition of international collaboration, bringing together physical oceanographers with regional expertise and a rich collection of ocean data to contribute to this annual assessment. While global ocean observation has evolved in the past decade, greatly increasing in volume and complexity, the WGOH-IROC continues to be a key link between regional ocean monitoring and research, and actual policy advice. Looking toward the future, ICES-WGOH has much to offer the burgeoning GOOS community, including a history of observations in key areas of the ocean and experience in meeting the needs of fisheries scientists. However, further engagement with GOOS is essential. WGOH will continue to track key observational timeseries, stressing continuity and quality while working to incorporate these data into the GOOS system.

\section{DATA AVAILABILITY}

The datasets analyzed for the IROC discussed in this white paper can be downloaded at the IROC online web page https://ocean. ices.dk/iroc/

\section{AUTHOR CONTRIBUTIONS}

CG-P conceived the white paper and coordinated the group. CG-P, PF, KL, and $\mathrm{NH}$ designed the paper structure and defined the key contents. CG-P took the lead in writing the manuscript and PF performed thorough draft reviews. RG analyzed the characteristics of the collection of timeseries and created a graphical representation of the outcome. All authors commented on the manuscript providing specific feedback.

\section{FUNDING}

The work carried out over the years by the WGOH under the auspices of ICES is supported by many monitoring programs across the North Atlantic and Arctic regions, either run by working group members hosting institutions or other institutions/consortia. WGOH work and meetings are possible through the economical commitment of ICES member countries.

\section{ACKNOWLEDGMENTS}

The authors wish to thank ICES for promoting international networking through expert groups, WGOH members hosting institutions for sponsoring their active participation in the Working Group and all institutions/projects/people behind the IROC timeseries collection. 


\section{REFERENCES}

Berx, B., and Payne, M. R. (2017). The Sub-Polar Gyre Index - a community data set for application in fisheries and environment research. Earth Syst. Sci. Data 9, 259-266. doi: 10.5194/essd-9-259-2017

Brander, K. M. (2018). Climate change not to blame for cod population decline. Nat. Sustainabil. 1, 262-264. doi: 10.1038/s41893-018-0081-5

Dickey-Collas, M. (2014). Why the complex nature of integrated ecosystem assessments requires a flexible and adaptive approach. J. Mar. Sci. 71, 11741182. doi: 10.1093/icesjms/fsu027

Gaillard, F., Reynaud, T., Thierry, V., Kolodziejczyk, N., and von Schuckmann, K. (2016). In situ-based reanalysis of the global ocean temperature and salinity with ISAS: Variability of the heat content and steric height. J. Clim. 29, 1305-1323. doi: 10.1175/jcli-d-15-0028.1

González, D., Coughlan, C., Stipsand, A., Stolkand, A., González-Pola, C., MorenoAranda, I., et al. (2016). Review of the Commission Decision 2010/477/EU concerning MSFD criteria for assessing Good Environmental Status, Descriptor 7. Joint Research Centre Technical Reports, EUR 27544 EN. doi: 10.2788/ 435059

González-Pola, C., Larsen, K., Fratantoni, P., and Beszczynska-Möller, (eds.). (2018). ICES Report on Ocean Climate 2017. ICES Cooperative Research Report No. 345. doi: $10.17895 /$ ices.pub. 4625

Halpert, M. S. and Bell, G. D. (1997). Climate assessment for 1996. Bull. Am. Meteorol. Soc. 78, S1-S50. doi: 10.1175/1520-0477-78.5s.s1

Hartfield, G., Blunden, J., and Arndt, D. S. (2018). State of the climate in 2017. Bull. Am. Meteorol. Soc. 99, Si-S310. doi: 10.1175/2018bamsstateoftheclimate.1

Hátún, H., and Chafik, L. (2018). On the recent ambiguity of the North Atlantic Subpolar Gyre Index. J. Geophys. Res. Oceans 123, 5072-5076. doi: 10.1029/2018JC014101

Holliday, N. P., and Cunningham, S. A. (2013). The extended Ellett Line: discoveries from 65 years of marine observations west of the UK. Oceanography 26, 156-163. doi: 10.5670/oceanog.2013.17

Holliday, N. P., Hughes, S. L., Bacon, S., Beszczynska-Möller, A., Hansen, B., et al. (2008). Reversal of the 1960s to 1990s freshening trend in the northeast North Atlantic and Nordic Seas. Geophys. Res. Lett. 35:L03614. doi: 10.1029/2007GL032675

Holliday, N. P., Valdimarsson, H., Nolan, G., Hughes, S., Lavín, A., Østerhus, S., et al. (2010). "The ICES Working Group on Oceanic Hydrography: building on over 100 years of North Atlantic observations," in Proceedings of OceanObs' 09: Sustained Ocean Observations and Information for Society, Venice, Vol. 2, eds J. Hall, D. Harrison, and D. Stammer (Noordwijk: European Space Agency), 501-507.

Holt, J., Hughes, S., Hopkins, J., Wakelin, S. L., Holliday, N. P., Dye, S., et al. (2012). Multi-decadal variability and trends in the temperature of the northwest European continental shelf: A model-data synthesis. Progr. Oceanogr. 106, 96-117. doi: 10.1016/j.pocean.2012.08.001

Hughes, S. and Holliday, N., editors (2006). ICES Report on Ocean Climate 2005. ICES Cooperative Research Report No. 280.

Hughes, S., and Lavín, A., (eds.). (2004). The Annual ICES Ocean Climate Status Summary 2003/2004. ICES Cooperative Research Report No. 269.

Hughes, S. L., Holliday, N. P., and Gaillard, F. (2012). Variability in the ICES/NAFO region between 1950 and 2009: observations from the ICES Report on Ocean Climate. J. Mar. Sci. 69, 706-719. doi: 10.1093/icesjms/fss044

ICES (1977). ICES Annual Report 1976. Copenhagen: ICES Headquarters.

ICES (2018). WGCHAIRS, 23-25 January 2018. ICES CM 2018/ACOM/ SCICOM:01. ICES Headquarters, Copenhagen.

IPCC (1990). Climate Change: The IPCC Scientific Assessment. Report prepared for Intergovernmental Panel on Climate Change by Working Group I. Cambridge, New York, NY; Melbourne, VIC: Cambridge University Press.
IPCC (2013). Climate Change 2013: The Physical Science Basis. Contribution of Working Group I to the Fifth Assessment Report of the Intergovernmental Panel on Climate Change. Cambridge; New York, NY: Cambridge University Press. doi: 10.1017/CBO9781107415324

Mork, K. A., Skagseth, Ø., Ivshin, V., Ozhigin, V., Hughes, S. L., and Valdimarsson, H. (2014). Advective and atmospheric forced changes in heat and fresh water content in the Norwegian Sea, 1951-2010. Geophys. Res. Lett. 41, 6221-6228. doi: $10.1002 / 2014$ gl061038

Nøttestad, L., Krafft, B. A., Anthonypillai, V., Bernasconi, M., Langård, L., Mørk, H. L., et al. (2015). Recent changes in distribution and relative abundance of cetaceans in the Norwegian Sea and their relationship with potential prey. Front. Ecol. Evol. 2:83. doi: 10.3389/fevo.2014.00083

Punzón, A., Serrano, A., Sánchez, F., Velasco, F., Preciado, I., GonzálezIrusta, J., et al. (2016). Response of a temperate demersal fish community to global warming. J. Mar. Syst. 161, 1-10. doi: 10.1016/j.jmarsys.2016. 05.001

Riser, S. C., Freeland, H. J., Roemmich, D., Wijffels, S., Troisi, A., Belbéoch, M., et al. (2016). Fifteen years of ocean observations with the global Argo array. Nat. Clim. Change 6, 145-153. doi: 10.1038/nclimate2872

Rudnick, D. L. (2016). Ocean research enabled by underwater gliders. Ann. Rev. Mar. Sci. 8, 519-541. doi: 10.1146/annurev-marine-122414-033913

Townhill, B., Pinnegar, J., Tinker, J., Jones, M., Simpson, S., Stebbing, P., et al. (2017). Non-native marine species in north-west Europe: developing an approach to assess future spread using regional downscaled climate projections. Aquat. Conserv. 27, 1035-1050. doi: 10.1002/aqc.2764

Turrel, B., (ed.). (1999). The 1998/1999 ICES Annual Ocean Climate Status Summary. Annex S. in Report from the Working Group on Ocean Hydrography (WGOH) 1998, ICES CM 1999/C:8.

von Schuckmann, K., Traon, P.-Y. L., Smith, N., Pascual, A., Brasseur, P., Fennel, K., et al. (2018). Copernicus Marine Service Ocean State Report. Journal of Operational Oceanography, 11(sup1):S1-S142. doi: 10.1080/1755876x.2018.1489208

Widmer, C., Fox, C., and Brierley, A. (2016). Effects of temperature and salinity on four species of northeastern Atlantic scyphistomae (Cnidaria: Scyphozoa). Mar. Ecol. Progr. Ser. 559, 73-88. doi: 10.3354/meps11879

WMO (1994). WMO Statement on the Status of the Global Climate in 1993. WMO-No. 809, Geneva.

WMO (2018). WMO Statement on the State of the Global Climate in 2017. WMO-No. 1212. Geneva .

WMO-IOC (2018). Global Data buoy Observations, a DBCP Implementation Strategy, Fifteenth Edition. Technical report, Document No. 15, Geneva.

Yelland, M., Holliday, N., Skjelvan, I., Osterhus, S., and Conway, T. (2009). "Continuous observations from the weather ship Polarfront at station Mike," in OceanObs'09: Sustained Ocean Observations and Information for Society (Venice).

Conflict of Interest Statement: The authors declare that the research was conducted in the absence of any commercial or financial relationships that could be construed as a potential conflict of interest.

Copyright (c) 2019 González-Pola, Fratantoni, Larsen, Holliday, Dye, Mork, Beszczynska-Möller, Valdimarsson, Trofimov, Parner, Klein, Cisewski, Fontán, Lyons, Kolodziejczyk, Graña, Linders, Wodzinowski, Goszczko and Cusack. This is an open-access article distributed under the terms of the Creative Commons Attribution License (CC BY). The use, distribution or reproduction in other forums is permitted, provided the original author(s) and the copyright owner(s) are credited and that the original publication in this journal is cited, in accordance with accepted academic practice. No use, distribution or reproduction is permitted which does not comply with these terms. 